Acta Crystallographica Section A

Foundations of Crystallography

ISSN 0108-7673

Received 3 January 2007

Accepted 11 January 2007

\section{Response to Spackman's comment on On the calculation of the electrostatic potential, electric field and electric field gradient from the aspherical pseudoatom model}

\author{
Anatoliy Volkov* and Philip Coppens*
}

Department of Chemistry, University at Buffalo, State University of New York, Buffalo, NY 14260-3000, USA.

Correspondence e-mail: volkov@chem.buffalo.edu,coppens@buffalo.edu
(C) 2007 International Union of Crystallography Printed in Singapore - all rights reserved
Table 1

Root-mean-squared differences in electric field components $E_{x}$ and $E_{y}\left(\mathrm{e} \AA^{-2}\right)$ in the plane of the map between exact and EPMM calculations .

(R.m.s. values of $E_{x}$ and $E_{y}$ are $\sim 5.4$ and $\sim 6.5 \mathrm{e} \AA^{-2}$, respectively.)

\begin{tabular}{lllll}
\hline & $\begin{array}{l}8 \text { neighboring } \\
\text { molecules }\end{array}$ & $\begin{array}{l}\text { All atoms with } \\
-1<x, y, z<2\end{array}$ & $\begin{array}{l}\text { All atoms with } \\
-2<x, y, z<3\end{array}$ & $\begin{array}{l}\text { All atoms with } \\
-3<x, y, z<4\end{array}$ \\
\hline R.m.s. $\left(E_{x}\right)$ & $2 \times 10^{-6}$ & $1 \times 10^{-5}$ & $1 \times 10^{-5}$ & $1 \times 10^{-5}$ \\
R.m.s. $\left(E_{y}\right)$ & $2 \times 10^{-6}$ & $7 \times 10^{-6}$ & $1 \times 10^{-5}$ & $1 \times 10^{-5}$ \\
\hline
\end{tabular}

Table 2

Number of atoms and elapsed time (s) for each of the calculations (calculations were performed using Athlon64 $3400+2.2 \mathrm{GHz}$ processor with $1 \mathrm{MB}$ of L2 cache).

\begin{tabular}{|c|c|c|c|}
\hline \multirow[b]{2}{*}{ Calculation } & \multicolumn{2}{|c|}{ Elapsed CPU time (s) } & \multirow{2}{*}{$\begin{array}{l}\text { Number of atoms } \\
\text { used in the } \\
\text { calculation }\end{array}$} \\
\hline & Exact formulae & EPMM & \\
\hline 8 neighboring molecules & 5.2 & 4.3 & 48 \\
\hline All atoms with $-1<x, y, z<2$ & 54.5 & 13.6 & 642 \\
\hline All atoms with $-2<x, y, z<3$ & 254.5 & 40.7 & 2994 \\
\hline All atoms with $-3<x, y, z<4$ & 713.8 & 100.8 & 8226 \\
\hline All atoms with $-4<x, y, z<5$ & - & 216.5 & 17490 \\
\hline
\end{tabular}

Table 3

Root-mean-squared differences in electric field components $E_{x}$ and $E_{y}\left(\mathrm{e} \AA^{-2}\right)$ in the plane of the map relative to the values from calculation that included all atoms with $-4<x, y, z<5$ (all from EPMM calculations).

(R.m.s. values of $E_{x}$ and $E_{y}$ are $\sim 5.4$ and $\sim 6.5 \mathrm{e} \AA^{-2}$, respectively.)

\begin{tabular}{lllll}
\hline & $\begin{array}{l}8 \text { neighboring } \\
\text { molecules }\end{array}$ & $\begin{array}{l}\text { All atoms with } \\
-1<x, y, z<2\end{array}$ & $\begin{array}{l}\text { All atoms with } \\
-2<x, y, z<3\end{array}$ & $\begin{array}{l}\text { All atoms with } \\
-3<x, y, z<4\end{array}$ \\
\hline R.m.s. $\left(E_{x}\right)$ & 0.02 & 0.006 & 0.0007 & 0.00020 \\
R.m.s. $\left(E_{y}\right)$ & 0.03 & 0.004 & 0.0004 & 0.00009 \\
\hline
\end{tabular}

well aware of the existence of the Ewald summation techniques which we used previously in the calculation of the lattice energy of ionic ( $\mathrm{Su}$ \& Coppens, 1995) and molecular (Abramov, Volkov, Wu \& Coppens, 2000a,b; Abramov, Volkov \& Coppens, 2000) crystals. However, the direct-space summation was found to be advantageous in terms of both speed and ease of implementation when combined with the new EPMM method (Volkov et al., 2007).

MS states that we misunderstand the purpose of the methods described by Brown \& Spackman (1994) as several algorithms published in this paper were used only for debugging of the $V A L R A Y$ code and should not be considered of practical importance. 
Table 4

Components of the traceless EFG tensor at the nuclear positions in formamide (atomic units) from different methods.

\begin{tabular}{|c|c|c|c|c|c|c|}
\hline & $X X$ & $X Y$ & $X Z$ & $Y Y$ & $Y Z$ & $Z Z$ \\
\hline \multicolumn{7}{|l|}{$\mathrm{O}(1)$} \\
\hline PBE/6-31G** & -0.43 & -1.52 & 0.04 & 1.44 & 0.02 & -1.01 \\
\hline PBE/aug-cc-pVDZ & -0.41 & -1.50 & 0.03 & 1.37 & 0.02 & -0.96 \\
\hline PBE/aug-cc-pVDZ & -0.34 & -1.49 & 0.03 & 1.44 & 0.02 & -1.09 \\
\hline $\mathrm{XD} / \mathrm{PBE} / 6-31 \mathrm{G}^{* *}$ & -0.27 & -1.21 & -0.04 & 1.25 & 0.07 & -0.98 \\
\hline \multicolumn{7}{|l|}{$\mathrm{N}(2)$} \\
\hline $\mathrm{PBE} / 6-31 \mathrm{G}^{* *}$ & -0.61 & -0.03 & -0.05 & -0.66 & -0.01 & 1.27 \\
\hline PBE/aug-cc-pVDZ & -0.58 & -0.04 & -0.05 & -0.63 & -0.01 & 1.20 \\
\hline PBE/aug-cc-pVDZ & -0.56 & -0.03 & -0.05 & -0.59 & -0.01 & 1.15 \\
\hline $\mathrm{XD} / \mathrm{PBE} / 6-31 \mathrm{G}^{* *}$ & -0.39 & -0.02 & -0.02 & -0.45 & -0.02 & 0.85 \\
\hline \multicolumn{7}{|l|}{$\mathrm{C}(3)$} \\
\hline $\mathrm{PBE} / 6-31 \mathrm{G}^{* *}$ & 0.13 & 0.08 & 0.00 & 0.33 & 0.00 & -0.46 \\
\hline PBE/aug-cc-pVDZ & 0.16 & 0.08 & 0.00 & 0.34 & 0.00 & -0.49 \\
\hline PBE/aug-cc-pVDZ & 0.19 & 0.08 & 0.00 & 0.39 & 0.00 & -0.59 \\
\hline $\mathrm{XD} / \mathrm{PBE} / 6-31 \mathrm{G}^{* *}$ & 0.25 & 0.07 & 0.00 & 0.27 & -0.02 & -0.52 \\
\hline \multicolumn{7}{|l|}{$\mathrm{H}(4)$} \\
\hline $\mathrm{PBE} / 6-31 \mathrm{G}^{* *}$ & -0.32 & -0.42 & -0.02 & -0.06 & -0.01 & 0.37 \\
\hline PBE/aug-cc-pVDZ & -0.31 & -0.43 & -0.02 & -0.05 & -0.01 & 0.37 \\
\hline PBE/aug-cc-pVDZ & -0.31 & -0.42 & -0.02 & -0.05 & -0.01 & 0.36 \\
\hline $\mathrm{XD} / \mathrm{PBE} / 6-31 \mathrm{G} * *$ & -0.33 & -0.44 & -0.02 & -0.04 & -0.01 & 0.37 \\
\hline \multicolumn{7}{|l|}{$\mathrm{H}(5)$} \\
\hline $\mathrm{PBE} / 6-31 \mathrm{G}^{* *}$ & 0.25 & 0.07 & 0.00 & -0.60 & 0.00 & 0.35 \\
\hline PBE/aug-cc-pVDZ & 0.26 & 0.07 & 0.00 & -0.60 & 0.00 & 0.35 \\
\hline PBE/aug-cc-pVDZ & 0.25 & 0.07 & 0.00 & -0.60 & 0.00 & 0.34 \\
\hline $\mathrm{XD} / \mathrm{PBE} / 6-31 \mathrm{G} * *$ & 0.27 & 0.07 & 0.00 & -0.62 & 0.00 & 0.35 \\
\hline \multicolumn{7}{|l|}{$\mathrm{H}(6)$} \\
\hline $\mathrm{PBE} / 6-31 \mathrm{G}^{* *}$ & 0.21 & 0.01 & 0.00 & -0.44 & -0.01 & 0.23 \\
\hline PBE/aug-cc-pVDZ & 0.22 & 0.02 & 0.00 & -0.47 & -0.01 & 0.24 \\
\hline PBE/aug-cc-pVDZ & 0.20 & 0.01 & 0.00 & -0.43 & -0.01 & 0.23 \\
\hline $\mathrm{XD} / \mathrm{PBE} / 6-31 \mathrm{G}^{* *}$ & 0.21 & 0.01 & 0.00 & -0.46 & 0.00 & 0.24 \\
\hline
\end{tabular}

Nevertheless, the methods were published and are thus in the public domain and subject to further discussion.

The 1957 statement that 'only the traceless EFG tensor is relevant in the computation of quantities such as nuclear quadrupole coupling constants measured in NMR or NQR experiments (Cohen \& Reif, 1957)' is the basis for criticism of our comparison of the elements of the unabridged tensor elements. The point was to verify that our expressions yield correct values, for which the unabridged tensor provides a more stringent test. Going from the total to the traceless definition is of course trivial. In fact XD2006, like Gaussian 03 (2004), automatically prints out both total and traceless components of the EFG tensor as well as the corresponding eigenvalues (Appendix $A$, Supplementary Material). ${ }^{\mathbf{1}}$ For completeness, the components of the traceless EFG tensor and its eigenvalues for formamide are given in Tables 4 and 5. They in no way contradict any of the statements presented in our original paper.

We agree that use of the Sternheimer correction (Sternheimer, 1986) is questionable and should be re-examined. However, any disagreement between our value and the most precise up-to-date determination of $Q\left({ }^{57} \mathrm{Fe}^{m}\right)$ (Dufek et al., 1995) is unlikely to be due to the use of the correction, which adds only $0.01 \times 10^{-28} \mathrm{~m}^{2}$ to the uncorrected value of $Q\left({ }^{57} \mathrm{Fe}^{m}\right)=0.11 \times 10^{-28} \mathrm{~m}^{2}$ (less than $10 \%$ ). Any disagreement is more likely to be due to experimental errors in the data, which are larger than the Sternheimer correction, as shown in our paper. Of course, this does not eliminate the need for more

\footnotetext{
${ }^{1}$ Supplementary material for this paper is available from the IUCr electronic archives (Reference: SH0187). Services for accessing this material are described at the back of the journal.
}

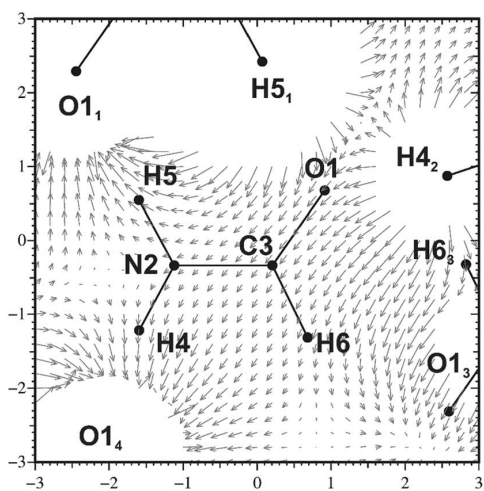

(a)

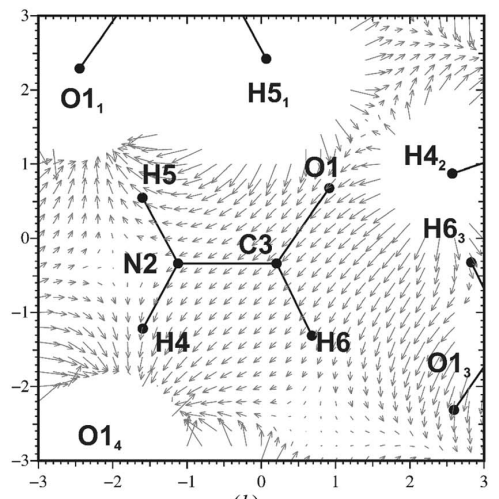

(b)
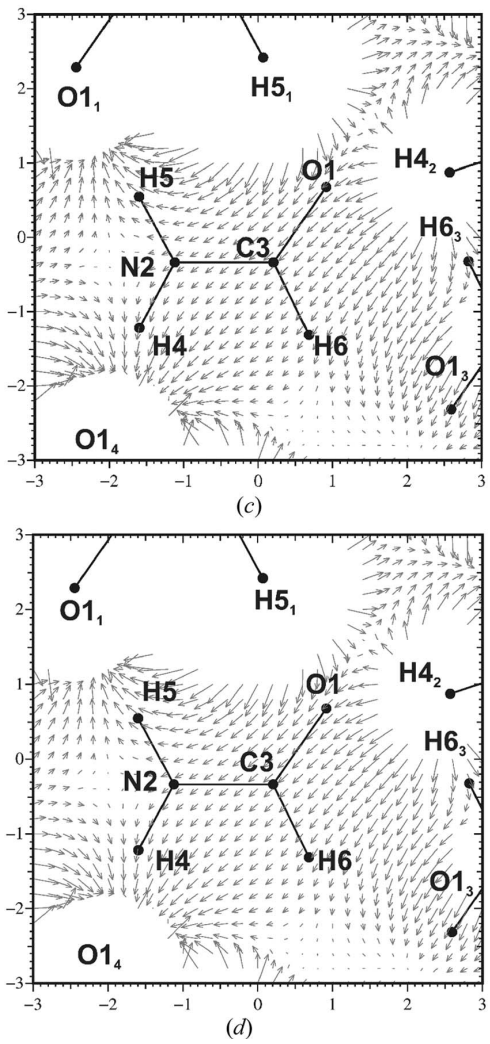

Figure 1

Electric field (EF) vectors in the $\mathrm{N} 2-\mathrm{C} 3-\mathrm{O} 1$ plane of the 'central' formamide molecule due to $(a)$ the eight nearest-neighbouring molecules in the crystal, and all atoms with fractional coordinates $(b)-1<x, y, z<2,(c)-2<x, y, z<3$ and (d) $-4<x, y, z<5$ (the contribution of the 'central' molecule to EF is not included). Subscripts of atom names identify the neighbouring molecules. Vectors with magnitudes larger than $0.15 \mathrm{e}^{-2}$ are omitted for clarity. The size of the map is $6 \times 6 \AA$ with a grid spacing of $0.2 \AA$. 
Table 5

Eigenvalues of the traceless EFG tensor at the nuclear positions in formamide (atomic units) from different methods.

\begin{tabular}{|c|c|c|c|}
\hline & $\lambda_{1}$ & $\lambda_{2}$ & $\lambda_{3}$ \\
\hline \multicolumn{4}{|l|}{$\mathrm{O}(1)$} \\
\hline $\mathrm{PBE} / 6-31 \mathrm{G} * *$ & -1.29 & -1.00 & 2.29 \\
\hline PBE/aug-cc-pVDZ & -1.27 & -0.95 & 2.22 \\
\hline PBE/aug-cc-pVDZ & -1.20 & -1.08 & 2.28 \\
\hline $\mathrm{XD} / \mathrm{PBE} / 6-31 \mathrm{G}^{* *}$ & -0.98 & -0.94 & 1.92 \\
\hline \multicolumn{4}{|l|}{$\mathrm{N}(2)$} \\
\hline $\mathrm{PBE} / 6-31 \mathrm{G}^{* *}$ & -0.68 & -0.59 & 1.27 \\
\hline PBE/aug-cc-pVDZ & -0.65 & -0.56 & 1.20 \\
\hline PBE/aug-cc-pVDZ & -0.61 & -0.54 & 1.15 \\
\hline $\mathrm{XD} / \mathrm{PBE} / 6-31 \mathrm{G}^{* *}$ & -0.46 & -0.39 & 0.85 \\
\hline \multicolumn{4}{|l|}{$\mathrm{C}(3)$} \\
\hline $\mathrm{PBE} / 6-31 \mathrm{G} * *$ & -0.46 & 0.10 & 0.35 \\
\hline PBE/aug-cc-pVDZ & -0.49 & 0.13 & 0.37 \\
\hline PBE/aug-cc-pVDZ & -0.59 & 0.16 & 0.42 \\
\hline $\mathrm{XD} / \mathrm{PBE} / 6-31 \mathrm{G}^{* *}$ & -0.52 & 0.19 & 0.33 \\
\hline \multicolumn{4}{|l|}{$\mathrm{H}(4)$} \\
\hline $\mathrm{PBE} / 6-31 \mathrm{G}^{* *}$ & -0.63 & 0.26 & 0.37 \\
\hline PBE/aug-cc-pVDZ & -0.63 & 0.26 & 0.37 \\
\hline PBE/aug-cc-pVDZ & -0.63 & 0.26 & 0.37 \\
\hline $\mathrm{XD} / \mathrm{PBE} / 6-31 \mathrm{G}^{* *}$ & -0.65 & 0.28 & 0.37 \\
\hline \multicolumn{4}{|l|}{$\mathrm{H}(5)$} \\
\hline $\mathrm{PBE} / 6-31 \mathrm{G} * *$ & -0.61 & 0.25 & 0.35 \\
\hline PBE/aug-cc-pVDZ & -0.61 & 0.26 & 0.35 \\
\hline PBE/aug-cc-pVDZ & -0.60 & 0.26 & 0.35 \\
\hline $\mathrm{XD} / \mathrm{PBE} / 6-31 \mathrm{G} * *$ & -0.62 & 0.28 & 0.35 \\
\hline \multicolumn{4}{|l|}{$\mathrm{H}(6)$} \\
\hline $\mathrm{PBE} / 6-31 \mathrm{G} * *$ & -0.44 & 0.21 & 0.23 \\
\hline PBE/aug-cc-pVDZ & -0.47 & 0.22 & 0.24 \\
\hline PBE/aug-cc-pVDZ & -0.43 & 0.20 & 0.23 \\
\hline $\mathrm{XD} / \mathrm{PBE} / 6-31 \mathrm{G}^{* *}$ & -0.46 & 0.21 & 0.24 \\
\hline
\end{tabular}

accurate experimentation and re-examination of the importance of the core polarization.

Financial support of this work by the National Science Foundation (CHE0236317) is gratefully acknowledged.

\section{References}

Abramov, Yu. A., Volkov, A. \& Coppens, P. (2000). J. Mol. Struct. (Theochem.), 529, 27-35.

Abramov, Yu. A., Volkov, A., Wu, G. \& Coppens, P. (2000a). Acta Cryst. A56, 585-591.

Abramov, Yu. A., Volkov, A., Wu, G. \& Coppens, P. (2000b). J. Phys. Chem. B104, 2183-2188.

Brown, A. S. \& Spackman, M. A. (1994). Mol. Phys. 83, 551-566.

Cohen, M. H. \& Reif, F. (1957). Solid State Phys. Adv. Res. Applic. 5, 321-438.

Cummins, P. G., Dunmur, D. A., Munn, R. W. \& Newham, R. J. (1976). Acta Cryst. A32, 847-853.

Dufek, P., Blaha, P. \& Schwarz, K. (1995). Phys. Rev. Lett. 25, 3545-3548.

Gaussian 03 (2004). Revision C.02, by M. J. Frisch et al. Gaussian, Inc., Wallingford, CT, USA.

Sternheimer, R. M. (1986). Z. Naturforsch. Teil A, 41, 24-36.

Su, Z. \& Coppens, P. (1995). Acta Cryst. A51, 27-32.

Volkov, A., King, H. F., Coppens, P. \& Farrugia, L. J. (2006). Acta Cryst. A62, $400-408$.

Volkov, A., King, H. F., Coppens, P. \& Macchi, P. (2007). In preparation.

Volkov, A., Koritsanszky T. S. \& Coppens, P. (2004). Chem. Phys. Lett. 391, 170-175.

Volkov, A., Macchi, P., Farrugia, L. J., Gatti, C., Mallinson, P., Richter, T. \& Koritsanszky, T. (2006). XD2006 - A Computer Program Package for Multipole Refinement, Topological Analysis of Charge Densities and Evaluation of Intermolecular Energies from Experimental or Theoretical Structure Factors. University at Buffalo, State University of New York, NY, USA; University of Milano, Italy; University of Glasgow, UK; CNRISTM, Milano, Italy; Middle Tennessee State University, TN, USA. 